\title{
Conferência
}

\section{Articulações sobre a "Conferência Justiça e Paz para o desenvolvimento humano" e a encíclica Pacem in Terris}

\author{
Articulations on the Justice and Peace \\ Conference for human development and \\ the Pacem In Terris encyclical
}

Ricardo Chiminazzo ${ }^{1}$

(iD) 0000-0001-6698-7299

\begin{abstract}
Resumo
Trata-se de um exercício de cotejar as ideias e premissas lançadas durante a conferência "Justiça e paz para o desenvolvimento humano integral" e relacioná-las à encíclica papal Pacem in Terris como forma de expandir os pontos de vistas sobre o tema e mostrar a atualidade do documento papal.
\end{abstract}

Palavras-chave: Papa Francisco. paz. Desenvolvimento humano. Encíclica. Joao XXIII.

\begin{abstract}
It is an exercise of analyses of ideas and premises launched during the Conference "Justice and Peace for Integral Human Development" due the papal encyclical Pace in Terris as a way to expand the points of view on the subject and show that the papal document is still actual.
\end{abstract}

Keywords: Francisco Pope. Peace. Humam development. Joao XXIII. Encliclyc.

\section{Introdução}

Se, isoladamente, os temas justiça, paz e desenvolvimento humano integral seriam suficientes para gerar análises, reflexões complexas e praticamente infinitas, falar em justiça e paz para o desenvolvimento humano integral, título que aglutina os citados temas, também exala um potencial para uma miríade de abordagens em diversos ângulos.

A conferência "Justiça e paz para o desenvolvimento humano integral" (2019), apresentou uma abordagem com leveza, porém sem perder a seriedade e profundidade do tema proposto, e

\footnotetext{
1 Pontifícia Universidade Católica de Campinas, Centro de Ciências Humanas e Sociais Aplicadas, Programa de Pós-Graduação em Ciências da Religião. R. Prof. Dr. Euryclides de Jesus Zerbini, 1516, Parque Rural Fazenda Santa Cândida, 13087-571, Campinas, SP, Brasil. E-mail: rchiminazzo@gmail.com
} 
focou principal e especialmente na questão da pobreza como fator de (falta) de desenvolvimento humano.

Achou por bem a conferencista informar que entende que "vivemos tempos de Francisco" ao defender que o atual Papa mostra a coerência entre seu discurso e seus atos no que tange ao exigir que o clero atenda os pobres com mais atenção, pontuou que acredita que existam movimentos internos contrários às suas boas intenções e que, mesmo fora da Igreja, mas ainda dentre os fiéis, muitas pessoas não compreendem o alcance de seu discurso. Exemplificou citando o caso da italiana que se revoltou contra a fala do Papa, que disse que os países precisam ser mais respeitosos com os imigrantes.

O citado exemplo e algumas "provocações" (entendidas como um chamado à meditação diante da gravidade do problema, sem desenvolver o assunto em profundidade) direcionadas para a plateia, como sobre a quantidade de empregos disponíveis no futuro e se o diploma universitário seria um fator de garantia de colocação profissional, foram rápidas exceções em uma palestra que abordou a pobreza e, em especial, como a Igreja Católica a encara.

Chama a atenção que em dado momento a conferencista questiona quem conhece a doutrina social da Igreja, alegando que se trata de um "tesouro escondido" sobre a abordagem da Igreja sobre a questão da pobreza. Ocorre, porém, que ao contrário da impressão que a conferência pode deixar, existem outros "tesouros escondidos" e outros papas cujas atuações podem atender aos temas.

O objetivo deste trabalho não é contrapor o que foi apresentado na conferência, mas dar conhecimento sobre um desses papas, cuja atuação destacada rompeu a inércia da Igreja a ponto de ser canonizado e chamado de santo, e uma de suas encíclicas.

Esse papa é São João XXIII, cuja biografia e encíclica Pacem in Terris, escrita em 1963, traz um conteúdo atual até os presentes dias, fornecendo abordagens sobre o desenvolvimento humano muito além das apresentadas na Conferência.

\section{Pacem in Terris}

\section{Sobre São João XXIII: o Papa bom}

O italiano de Soto II Monte Angelo Giuseppe Roncalli ingressou no seminário aos 11 anos de idade, onde começou a redigir cadernos espirituais, prática que manteve até sua morte.

Quatro anos depois, foi admitido na Ordem Franciscana Secular. Foi ordenado padre em 1904 e no ano seguinte se tornou secretário do bispo de Bergamo, Giacomo Maria Radini Tedeschi. Nesse período, acompanhou o bispo em visitas pastorais e elaborou diversas iniciativas. Durante a primeira guerra foi convocado, serviu no corpo médico e foi capelão dos soldados feridos.

Ao final da guerra, abriu uma casa para atender as necessidades espirituais dos estudantes, depois foi nomeado diretor do seminário - onde ficou por dois anos antes de ser chamado para trabalhar na Santa Sé, em Roma.

Durante o papado de Benedito XV, passou a ocupar o posto de presidente nacional do Conselho das Obras Pontifícias para a Propagação da Fé e foi nomeado para representar o Papa 
como visitador apostólico na Bulgária durante o papado de Pio XI. Em 1925 foi ordenado bispo (SANTA SÉ, 2014).

Ficou na Bulgária entre 1925 e 1934 visitando comunidades católicas e promovendo relações entre comunidades cristãs e, em 1935, visitou a Turquia e a Grécia como delegado apostólico, onde trabalhou em um diálogo respeitoso com ortodoxos e muçulmanos.

Estava na Grécia quando eclodiu a Segunda Guerra Mundial e - em 1944 -, foi nomeado núncio apostólico ${ }^{2}$ em Paris, tornando-se representante da Santa Sé na França. Ao final do conflito mundial ajudou os prisioneiros de guerra a retornarem à vida religiosa, visitando santuários e participando de manifestações litúrgicas.

Em 1953, tornou-se cardeal pelas mãos do Papa Pio XII e passou a trabalhar como patriarca local de Veneza. Tornou-se Papa em 1958, em um conclave que durou quatro dias e teve 11 votações.

O fato de ele ter sido escolhido como papa, já idoso e reconhecidamente um homem simples e modesto, dava sinais de que o colégio cardinalício queria um "papa de transição", porém seus atos levaram a uma gestão supreendentemente inovadora.

Hanna Arendt dá o tom sobre o papado de João XXIII:

Quem me chamou a atenção para tais perguntas de modo simples e inequívoco foi uma camareira romana que, um dia, me disse: 'Senhora, esse Papa era um verdadeiro cristão. Como foi possível? E como pôde acontecer que um verdadeiro cristão se sentasse no trono de São Pedro? Ele não teve que ser primeiro nomeado bispo, arcebispo e cardeal antes de ser, finalmente, eleito papa? Ninguém se deu conta de quem ele realmente era?'.

Bem a resposta à última de suas três perguntas parece ser 'não'. Ele não estava entre os papáveis quando entrou no conclave; e os alfaiates vaticanos não tinham preparado nenhum hábito de seu tamanho. Ele foi eleito porque os cardeais não conseguiram entrar em acordo e estavam convencidos de que, como ele mesmo escreveu, 'eu seria um papa de provisória transição', sem muitas consequências. 'No entanto', continuava, 'aqui estou eu, já às vésperas do quarto ano do meu pontificado, com um imenso programa de trabalho na minha frente para ser realizado perante os olhos do mundo inteiro, que olha e espera'.

O que surpreende não é tanto o fato de ele não ser contato entre os papáveis, mas que alguém possa ter pensado que ele era uma figura sem consequências. No entanto, tudo isso é desconcertante apenas retrospectivamente (A VERDADEIRA..., 2019, online).

Seu papado durou cinco anos, período em que escreveu oito encíclicas. Ficou conhecido pelo rejuvenescimento e internacionalização do Colégio Cardinalício, pela intensificação das

\footnotetext{
2 Representante diplomático da Santa Sé, não do Estado da Cidade do Vaticano. Exerce o posto de embaixador representando a Santa Sé perante o Estado e a igreja local.
} 
relações diplomáticas com líderes políticos mundiais, em especial os da antiga União Soviética - o que contribuiu para minimizar a tensão entre cristãos e comunistas -, além da criação da Comissão para Unidade Cristã, que tinha como objetivo estabelecer laços amistosos com as igrejas protestantes e ortodoxas.

Como se não bastasse, ainda instituiu uma comissão para rever o Código de Direito Canônico e passou a valorizar os episcopados locais.

Sua contribuição mais notável, no entanto, talvez tenha sido preparar a Igreja para tempos mais modernos através da convocação do Concílio Vaticano II.

O Papa João XXIII morreu em 1963 antes do encerramento do Concílio e foi sucedido pelo Papa Paulo VI. Seu pontificado foi reflexo de sua carreira: proximidade das pessoas e comunidades e estabelecimento de um diálogo inter-religioso.

Seu processo de canonização teve início em 1965 e se estendeu até 2014, quando o Papa Francisco dispensou a comprovação do seu segundo milagre. Curiosamente, o longo processo teve fim em uma cerimônia que celebrou também a canonização do Papa João Paulo II, cujo processo para ser declarado santo foi dos mais rápidos da história.

\section{A encíclica propriamente dita}

A encíclica Pacem in Terris foi publicada em abril de 1963, em um contexto político internacional diverso do que se experimenta em 2021: o mundo vivia a chamada "Guerra Fria", polarização mundial protagonizada pela extinta União Soviética e os Estados Unidos e suas representações político ideológicas: a primeira liderava um grupo de países chamados de "bloco comunista" e o segundo liderava o chamado "bloco capitalista". Apesar disso, o mundo vivia uma ascensão econômica pós-guerra que gerava desigualdades sociais.

Hoje os Estados Unidos mantêm algum protagonismo, porém seu antagonista ora é a China ora a Rússia, dependendo do tema em conflito. A despeito disso, os temas abordados na encíclica não poderiam ser mais aplicáveis aos dias de hoje a ao tema do desenvolvimento humano na justiça e na paz.

O Papa São João XXXIII impôs uma agenda de renovação na Igreja, iniciou o "Concílio Vaticano II, cuja característica mais importante era a abertura e seu diálogo positivo com o mundo moderno" (AQUINO JUNIOR, 2021) e, diferentemente do que foi feito em outras encíclicas, não apenas as dirigiu aos bispos, padres e fiéis, mas também a "todas as pessoas de boa vontade".

A encíclica se divide em cinco partes:

a) Primeira parte: ordem entre os seres humanos;

b) Segunda parte: relação entre as pessoas e os poderes públicos no seio das comunidades políticas;

c) Terceira parte: relação entre as comunidades políticas;

d) Quarta parte: relação entre as pessoas e as comunidades políticas com a comunidade mundial; 
e) Quinta parte: diretrizes pastorais.

O Papa começa dizendo que todo ser humano é pessoa, sujeito de direitos e deveres, que existe uma reciprocidade, uma equidade, uma correlação estreita de direitos e deveres entre pessoas diversas, sustentadas na colaboração mútua, no senso de responsabilidade e na convivência fundada na verdade, justiça, no amor e na liberdade.

Na primeira parte da encíclica, uma recomendação se destaca, já que encontra eco em uma das grandes preocupações do mundo atual: as chamadas fake news ou notícias falsas.

Dizia o Papa em 1963 que:

Todo ser humano tem direito natural ao respeito da sua dignidade e à boa fama; direito à liberdade na pesquisa da verdade e, dentro dos limites da ordem moral e do bem comum, à liberdade na manifestação do pensamento, bem como no cultivo da arte. Tem direito também a informação verídica sobre os acontecimentos públicos (JOÃO XXIII, 1963, online).

A exposição toma contornos proféticos ao se verificar a manifestação do Conselho Nacional de Justiça: "A desinformação, comumente chamada de fake news, é um dos maiores problemas da sociedade mundial e, no Brasil, não é diferente" (PAINEL..., 2019). Segundo a imprensa, o povo brasileiro é o mais preocupado com a propagação de informações falsas (ROSSI, 2021).

Em uma época em que sequer havia internet, o Papa defendia o direito à informação verídica como forma de desenvolvimento humano integral: o que diria ele a respeito deste momento em que existe uma enorme dificuldade em se aferir a veracidade de informações e em que grupos políticos montam aparatos de desinformação?

Muito antes de 1988, quando a Constituição Federal brasileira garantiu o direito de imagem, dignidade e boa fama - o que ensejaria no mundo jurídico a defesa do "dano moral" - e antes mesmo da Lei Geral de Proteção de Dados -, Lei n¹3.709/2018 (BRASIL, 2018, online), que entrou em vigência integralmente em 2021, preverem proteção à "boa fama" dos indivíduos na rede mundial de computadores e suas repercussões sociais, a encíclica já previa defesa como direito natural do ser humano.

O direito de emigração e de imigração, que perfeitamente pode ser combinado com o problema dos refugiados políticos, defendidos pelo Papa São João XXIII há 58 anos, também não envelheceram, conforme citado na própria conferência supramencionada (JUSTIÇA..., 2019), visto que é enorme a preocupação do Papa Francisco com o afluxo de refugiados que inicialmente fugiam de guerras e conflitos na África e no Oriente Médio e agora fogem da pandemia de coronavírus (LIGERO, 2021).

A encíclica exorta, por diversas vezes, a participação das pessoas na vida pública e política, outro assunto recorrente em um período nacional de grande polarização política: o cristão deve se envolver em assuntos sociais e políticos na defesa do ser humano.

Outro tema que não passa desapercebido e que tem grande apelo atual é o tratamento das minorias: 
Assim dentro de uma nação vivem não raro minorias de raça diferente e daí surgem graves problemas. Deve-se declarar abertamente que é grave injustiça qualquer ação tendente a reprimir a energia vital de alguma minoria, e muito mais se tais maquinações intentam extermina-las (JOÃO XXIII, 1963, online).

Impossível ver essa consideração do Papa e não correlacionar com as recentes manifestações do Black Lives Matter, movimento deflagrado por conta de uma sequência de violências perpetradas pela polícia dos Estados Unidos contra cidadãos negros e cuja repercussão ganhou o mundo e teve adesão de várias pessoas públicas e de celebridades.

A proteção e tratamento de todas as pessoas, independente de sua raça, é fator primordial do desenvolvimento humano integral.

Ao falar dos direitos inerentes à atividade econômica e do direito ao trabalho é possível ver que há uma convergência entre a encíclica e a "provocação" da conferencista (JUSTIÇA..., 2019) no que tange à sua preocupação com o fato de um diploma garantir ou não um emprego, ainda mais em um mundo no qual novas tecnologias substituem o trabalho humano e modificam a relação do homem com o trabalho:

Ao dever pessoal de trabalhar, inerente à natureza, corresponde um direito igualmente natural, o de poder o homem exigir que das tarefas realizadas Ihe provenham, para si e seus filhos, os bens indispensáveis à vida: tão categoricamente impõe a natureza a conservação do homem (JOÃO XXIII, 1963, online).

Assim, ao falar de paz, de diálogo, de dignidade e de justiça como caminhos para a dignidade humana, Pace in Terris mostra que não caducou ou envelheceu, mas continua sendo uma bússola a apontar o caminho da Igreja como instrumento de Justiça Social e Desenvolvimento Humano.

Fica aqui o registro de que o sucessor do Papa São João XXIII, Papa Paulo VI, dá sequência à questão do desenvolvimento humano em sua encíclica Populorum e Progressium.

\section{"Tempos de Francisco" lembram "Tempos de João"?}

Considerando a exortação "vivemos tempos de Francisco" e considerando o que foi suscitado sobre a "pérola escondida" chamada Pace in Terris, não se pode escapar da comparação e da constatação de que ambos os papas guardam enormes similaridades em seus pontificados.

A cultura "de encontro" e a bondade de coração aproximam os dois papas. Antes do concílio, o Papa São João XXIII disse: "Quero uma igreja pobre para os pobres" e, curiosamente, é a mesma frase com a qual o Papa Francisco inicia seu pontificado (SANTOS, 2014).

O diálogo inter-religioso também está arraigado no Papa Francisco e pôde ser visto quando ele lavou os pés de doze pessoas, inclusive de dois muçulmanos, por ocasião de uma celebração da páscoa (FRANCISCO..., 2013, online).

Em reportagem publicada pelo site G1, citando o historiados católico Thomas Cahill: 
Cahill escreveu a biografia de Joao XXIII e vê similaridades entre ele e Francisco: um homem simples, que parece incomodado com a pompa do Vaticano e teve a humildade de, em seu primeiro pronunciamento, em vez de abençoar os fiéis, pedir que eles o abençoassem (JOÃO..., 2014, online).

Outro artigo jornalístico diz que: "O argentino Jorge Mario Bergoglio reuniu em seu curto pontificado o que de melhor consta nos currículos do pontífice polonês Karol Wojtyla, o chamado 'papa da esperança', e do italiano Angello Roncari, o 'papa bom'" (CARDOSO; CRIVELLARO, 2016, online).

De outro lado, se o rompimento com uma inércia e um olhar voltado à modernização da Igreja são características que aproximam os papas, as críticas ferozes e a falta de adesão de alguns setores do clero são comuns a ambos os papados.

Há uma inegável semelhança entre as personalidades do Papa São João XXIII e do Papa Francisco e, muito além dessa semelhança, resta claro que os "Tempos de Francisco" devem muito ao legado dos "Tempos de João", pois um se assemelha demais ao outro.

\section{Considerações Finais}

A encíclica Pacem in Terris mantém um repertório temático atual e meditações perfeitamente aplicáveis sobre problemas que, se não foram erradicados, retornam com nova roupagem, como a questão da dignidade do trabalho em um mundo em que a tecnologia e a pandemia mudam as relações econômicas.

Não por acaso, é da lavra de um Papa cuja personalidade guarda enorme similaridade com o Papa atual, admirado por sua coerência e esforço de realmente por a Igreja "a caminho" 3 . Sua leitura, meditação e lições deveriam nortear as ações dos fiéis na busca e colaboração com seus irmãos para alcançar o desenvolvimento humano integral através da paz e da justiça.

\section{Referências}

A VERDADEIRA força de João XXIII: artigo de Hannah Arendt. São Leopoldo: Instituto Humanitas Unisinos, 2019. Disponível em: http://www.ihu.unisinos.br/170-noticias/noticias-2014/528444-a-verdadeira-forca-de-joao-xxiii-artigode-hannah-arendt. Acesso em: 1 ago. 2021.

AQUINO JUNIOR, F. Pacem in Terris: uma guia de leitura. Revista Eclesiástica Brasileira, v. 81, n. 318, p. 30-56, 2021. https://doi.org/10.29386/reb.v81i318.2564

BRASIL. Lei Geral de Proteção de Dados. Lei 13.709/2018. Brasília: Presidência da República, 2018. Disponível em: http://www.planalto.gov.br/ccivil_03/_ato2015-2018/2018/lei/13709.htm. Acesso em: 14 set. 2021.

CARDOSO, R.; CRIVELLARO, D. Os novos santos do papa Francisco. Istoé, 21 abr. 2016. Disponível em: https:/listoe. com.br/358055_OS+NOVOS+SANTOS+DO+PAPA+FRANCISCO/. Acesso em: 1 ago. 2021.

FRANCISCO é um novo João XXIII? O debate entre os historiadores. São Leopoldo: Instituto Humanitas Unisinos, 2013. Disponível em: http://www.ihu.unisinos.br/noticias/519066-francisco-e-um-novo-joao-xxiii-o-debate-entre-oshistoriadores. Acesso em: 1 ago. 2021.

\footnotetext{
${ }^{3}$ Igreja "a caminho" é uma expressão frequentemente usada pelos católicos para denotar que igreja como um todo precisa sair dos templos e enfrentar os problemas onde eles se encontram.
} 
JOÃO XXIII, Papa. Carta Encíclica Pacem in Terris. Vaticano: Libreria Editrice Vaticana, 1963. Disponível em: https://www. vatican.va/content/john-xxiii/pt/encyclicals/documents/hf_j-xxiii_enc_11041963_pacem.html. Acesso em: 29 set. 2021

JOAO XXIII, o "Papa bom", preparou a Igreja Carólica para os novos tempo. G1, 27 abr. 2014. G1 Mundo. Disponível em: http://g1.globo.com/mundo/noticia/2014/04/joao-xxiii-o-papa-bom-preparou-igreja-catolica-para-os-novos-tempos.html. Acesso em: 1 ago. 2021.

JUSTIÇA e paz para o desenvolvimento humando integral: conferência com Profa. Me. Rosana Manzini (Docente da Faculdade de Teologia da PUC-SP. Campinas: PUC-Campinas, 2019. 1 vídeo (1h11 min.). Publicado pelo canal PUC-Campinas. Disponível em: https://youtu.be/S3VFnWFulk0. Acesso em: 7 jul. 2021.

LIGERO, B. Crise dos refugiados : número de pessoas delocadas no mundo ultrapassa 80 milhões e deve piorar em 2021. Jovempan, 4 abr. 2021. Disponível em: https://jovempan.com.br/noticias/mundo/crise-dos-refugiados-numerode-pessoas-deslocadas-no-mundo-ultrapassa-80-milhoes-e-deve-piorar-em-2021.html. Acesso em: 1 ago. 2021.

PAINEL de checagem de Fake News. Conselho Nacional de Justiça, 1 abr. 2019. Programas e Ações. Disponível em: https://www.cnj.jus.br/programas-e-acoes/painel-de-checagem-de-fake-news/. Acesso em: 1 ago. 2021.

ROSSI, E. Universo digital: Brasil é o país mais preocupado do mundo com fake News. Istoé, 2021. Istoé Dinheiro. Disponível em: https://www.istoedinheiro.com.br/universo-digital-brasil-e-o-pais-mais-preocupado-do-mundo-com-fakenews. Acesso em: 30 ago. 2021.

SANTA SÉ. Perfil biográfico de João XXIII. Vaticano: Libreria Editrice Vaticana, 2014. Disponível em: https://www.vatican. va/content/john-xxiii/pt/biography/documents/hf_j-xxiii_bio_20190722_biografia.html. Acesso em: 29 jul. 2021.

SANTOS, A. Padre Joãozinho analisa legado dos papas João XVII e João Paulo II. Jornal Santuário, 24 abr. 2014. Disponível em: https://www.a12.com/jornalsantuario/noticias/padre-joaozinho-analisa-legado-dos-papas-joao-xvii-ejoao-paulo-ii. Acesso em: 1 ago. 2021. 